\title{
DISTRIBUIÇÃO E ASPECTOS METALOGENÉTICOS DAS OCORRÊNCIAS DE SCHEELITA NO PRÉ-CAMBRIANO DO ESTADO DE MINAS GERAIS, BRASIL
}

\author{
Ronaldo Mello Pereira (*) \& Ciro Alexandre Ávila (**)
}

\begin{abstract}
This paper presents a general description of six scheelite mineralized areas in Minas Gerais State, southeastern Brazil:

- Nazareno - São João Del Rei - Lagoa Dourada area where scheelite occurs confined to ortho amphibolitic rocks of the Barbacena Greenstone Belt;

- Iron Quadrangle area where most scheelite occurrences are related to a auriferous shear zones of the Nova Lima Group of the Rio das Velhas Greenstone Belt;

Itinga - Coronel Murta - Rubelita area in the Araçuai Fold Belt where scheelite is present in calcsilicate rocks interlayered with metasedimentary schists of the Macaubas Group and in quartz vein with wolframite;

- Galiléia-Mendes Pimentel area in Costeiro Fold Belt where scheelite mineralization occurs in calcsilicate layers and quartz veins, in schists of the São Tomé Group;

- Itamonte - Itanhandu area in the Ribeira Fold Belt where scheelite is related to greisen of leucocratic granitoids cupolas;

- Rio Manhuaçu - Mutum area in the Costeiro Folded Belt where the scheelite mineralization is present in calc-silicate xenoliths associated with granitic rocks of the Pocrane Complex.
\end{abstract}

\section{INTRODUÇÃO}

Quando se pensa no Estado de Minas Gerais, tanto do lado da produção mineral, quanto do ponto de vista prospectivo, associa-se, imediatamente, à presença, neste, de mineralizações de ouro, ferro, manganês, diamante e minerais de pegmatitos, sendo relegados a um plano secundário, importantes bens minerais, dos quais o Estado é, às vezes, significativo produtor, tais como nióbio, zinco, fosfato, calcário, níquel, etc.

Desta forma, não é de estranhar que, prospectivamente, outros tipos de bens minerais, que não constituem jazidas, como o tungstênio, não sejam sequer levados em consideração, quanto às suas potencialidades. Na tentativa de atrair as atenções para esse problema, será apresentada, a seguir, uma síntese das informações, atualmente disponíveis, relativas à presença de scheelita, em algumas áreas do Estado de Minas Gerais, onde são registradas inúmeras ocorrências deste mineral

\section{DISTRIBUIÇÃO DAS OCORRÊNCIAS DE SCHEELITA}

Um dos primeiros registros sobre a ocorrência de minerais de tungstênio no Estado de Minas Gerais devese a Graton (in Lindgren 1933), que menciona a presença de scheelita associada à paragênese aurífera da mina de ouro de Morro Velho. Posteriormente, outras ocorrências foram descritas por Ferraz (1929), Guimarães \& Coelho (1944), Magalhães \& Latorraca (1978), Cassedanne \& Cassedanne (1978), Cassedanne
\& Pereira (1982a), Santos \& Pereira (1983), Pereira \& Santos (1983), Pedrosa Soares et al. (1983), Pereira (1985), Monteiro (1986), Pereira et al. (1989), Pereira \& Ávila (1990), Scabora \& Penha (1992), Pereira et al. (1994) e Pereira et al. (1996).

Para uma melhor visualização da distribuição das regiões mineralizadas, agrupou-se as ocorrências de scheelita do Estado de Minas Gerais em 6 grandes áreas (Figura 1), destacando-se, na Tabela 1, as principais informações referentes a cada uma destas.

A primeira área corresponde à região de Nazareno - São João del Rei - Lagoa Dourada, onde pequenos grãos de scheelita pontificam xistos, anfibólio xistos, anfibolitos e anfibólio gnaisses ortoderivados, que ocorrem intercalados com metassedimentos, turmalinitos, cherts e rochas calciossilicáticas na sequência vulcano-sedimentar, pertencente ao Greenstone Belt Barbacena (Pereira et al. 1989; Pereira \& Ávila 1990), considerado como de idade arqueana (Pires \& Porto Jr. 1986). A segunda área engloba parte do Greenstone Belt Rio das Velhas no Quadrilátero Ferrífero, mais especificamente, os locais onde são registradas rochas metavulcânicas cisalhadas de composição básica e idade arqueana, pertencentes ao Grupo Nova Lima (Pereira \& Santos 1992). A terceira área localiza-se entre as cidades de Itinga, Coronel Murta e Rubelita, e encontra-se contida na Faixa Araçuaí (Almeida 1977), que engloba mica xistos e rochas calciossilicáticas do Grupo Macaúbas (Pedrosa Soares et al. 1983), correlacionado por Almeida \& Litwinski (1984) ao Proterozóico Médio. A quarta área em questão, situada na região de Galiléia-Mendes 


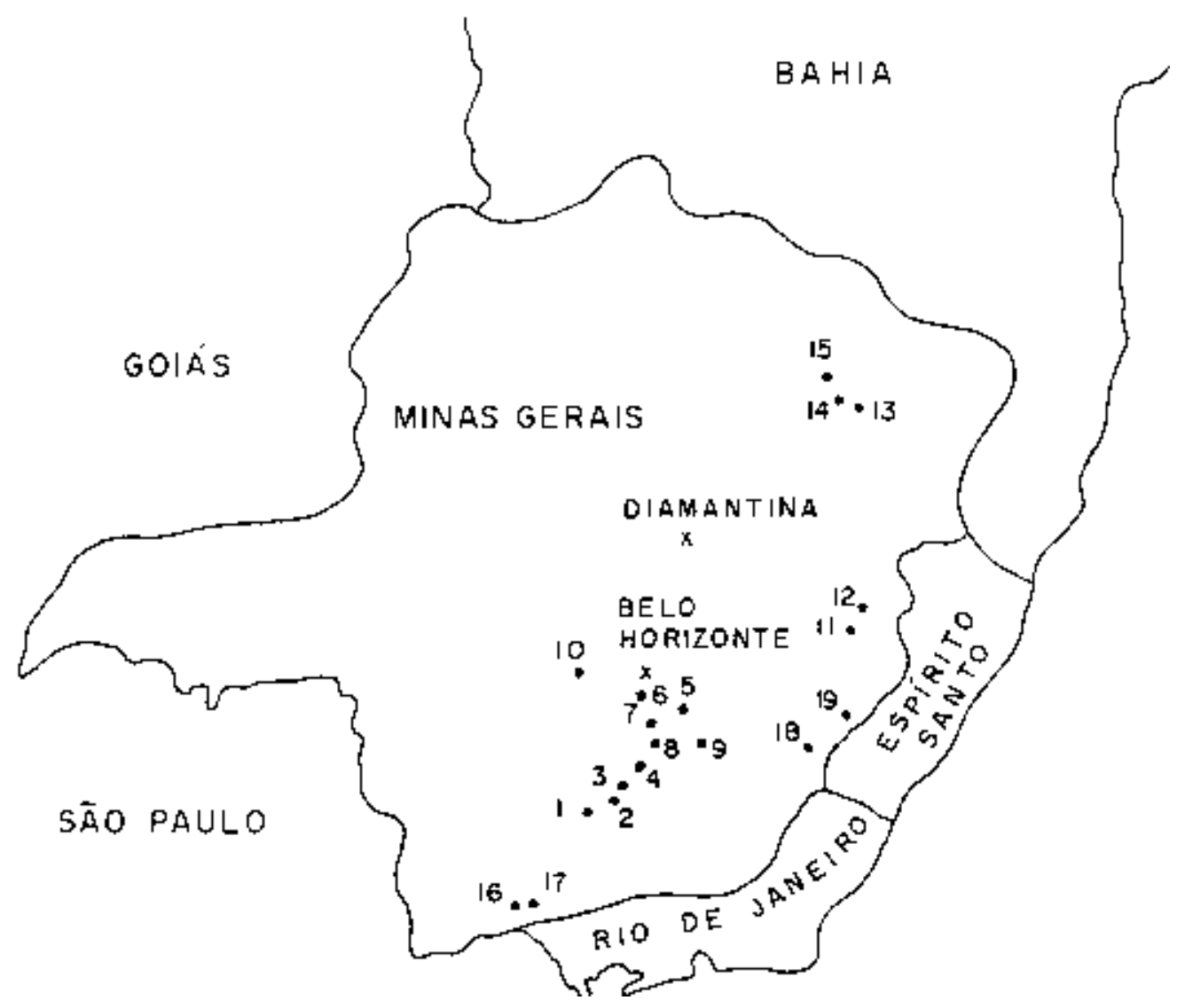

Figura 1: Distribuição das ocorrências de scheelita / wolframita no Estado de Minas Gerais.

Legenda: 1 - Nazareno - Cassiterita; 2 - São João del Rei; 3 - Coronel Xavier Chaves - Lagoa Dourada; 4 Entre Rios de Minas; 5 - Caeté; 6 - Nova Lima - Raposos; 7 - Honório Bicalho; 8 - Itabirito; 9 - Mariana; 10 Pitangui; 11 - Galiléia; 12 - Mendes Pimentel - Divino das Laranjeiras; 13 - Itinga; 14 - Coronel Murta; 15 Rubelita; 16 - Itanhandu; 17 - Itamonte; 18 - Manhuaçu; 19 - Mutum.

Figure 1: Distribution of the scheelite / wolframite occurrences in Minas Gerais, Brazil. Legende: 1 - Nazareno - Cassiterita; 2 - São João del Rei; 3 - Coronel Xavier Chaves - Lagoa Dourada; 4 Entre Rios de Minas; 5 - Caeté; 6 - Nova Lima - Raposos; 7 - Honório Bicalho; 8 - Itabirito; 9 - Mariana; 10 Pitangui; 11 - Galiléia; 12 - Mendes Pimentel - Divino das Laranjeiras; 13 - Itinga; 14 - Coronel Murta; 15 Rubelita; 16 - Itanhandu; 17 - Itamonte; 18 - Manhuaçu; 19 - Mutum.

Pimentel, encontra-se inserida no Grupo São Tomé (Silva et al. 1987), pertencente ao Cinturão Costeiro e compreende parte da Província Pegmatítica Oriental Brasileira, situando-se na região do Médio Rio Doce e incluindo os Xistos São Tomé, correlacionados por Inda et al. (1984) ao Arqueano, com retrabalhamento nos Eventos Transamazônico e Brasiliano. A quinta área, Itamonte-Itanhandu, localiza-se na Serra da Mantiqueira e pode ser considerada como fazendo parte da Faixa Ribeira, abrangendo metassedimentos précambrianos, correlacionados ao Ciclo Deposicional Andrelândia, cuja idade pode ser correlacionada ao Proterozóico Superior (Junho 1995). A sexta área abrange parte da região de Rio Manhuaçu-Mutum e encontra-se inserida no Complexo Pocrane, associado ao Cinturão Costeiro, que é constituído de xistos, gnaisses e níveis calciossilicáticos, admitidos como formados no Proterozóico Inferior e que são cortados por granitóides associados ao Evento Brasiliano (Silva et al. 1987).

\section{OCORRÊNCIAS DE SCHEELITA NA ÁREA DE NAZARENO-SÃO JOÃO DEL REI-LAGOA DOURADA}

A região de Nazareno-São João del Rei-Lagoa Dourada, localiza-se no sudeste do Estado de Minas Gerais e encontra-se representada por finas faixas de rochas vulcano-sedimentares tipo Greenstone. Cortando essa seqüência, podem ser observados diversos corpos intrusivos plutônicos, com composição petrográfica variando desde gabróica até granítica (Ávila 1992; Ávila \& Valença 1992) e idade transamazônica (Quemeneur \& Vidal 1989).

As rochas vulcano-sedimentares da região, apesar das diferentes denominações que lhes foram conferidas, correspondem na realidade a um conjunto composto de várias seqüências distintas, constituídas de rochas metaultramáficas com textura spinifex, xistos e anfibolitos ortoderivados, meta andesitos máficos, metadacitos-metariolitos e rochas metassedimentares 


\begin{tabular}{|c|c|c|c|c|c|c|c|c|c|c|c|c|c|c|c|c|c|c|c|c|c|}
\hline 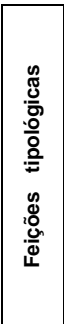 & 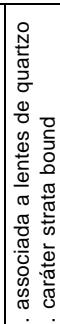 & 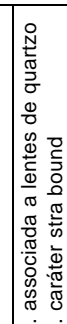 & & & 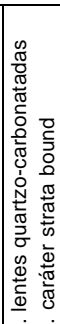 & 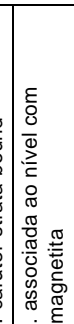 & & & & & & 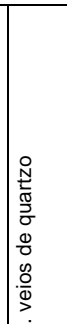 & & & 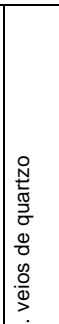 & 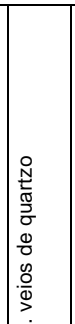 & $\mid$ & & & & \\
\hline 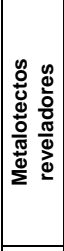 & 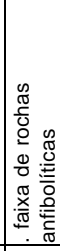 & 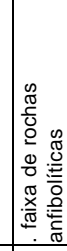 & & & 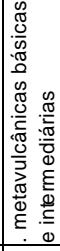 & 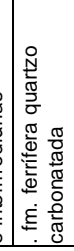 & & 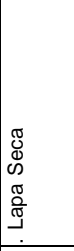 & 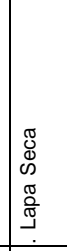 & 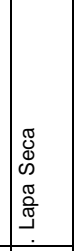 & & 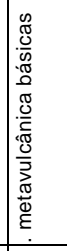 & & 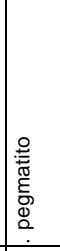 & 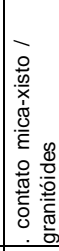 & 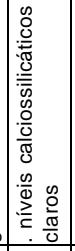 & 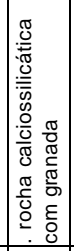 & 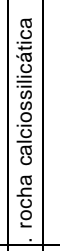 & & 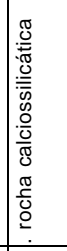 & \\
\hline $\begin{array}{l} \\
\frac{0}{0} \\
\underline{\pi} \\
\end{array}$ & $<$ & $\ll$ & . & & & $\varangle$ & & $\ll$ & $\ll$ & $\varangle$ & $\ll$ & $\ll$ & & s & $\ll$ & $\sum_{a}$ & $\sum_{0}$ & $\sum_{0}$ & & $\bar{\alpha}$ & \\
\hline 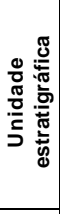 & 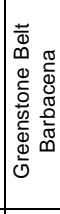 & 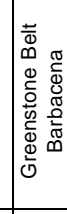 & . & & 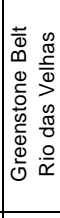 & & & 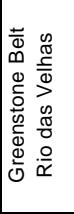 & 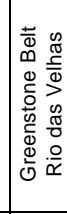 & 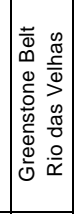 & 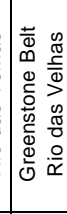 & 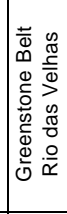 & & 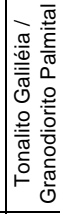 & 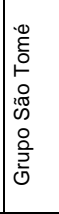 & 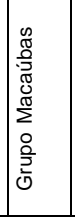 & 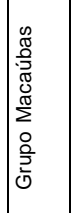 & 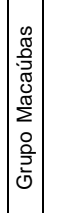 & & 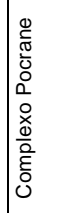 & \\
\hline 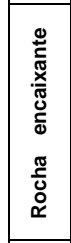 & 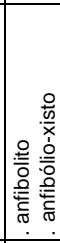 & 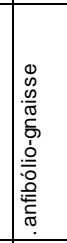 & ' & & 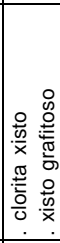 & & & 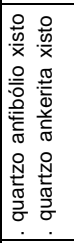 & 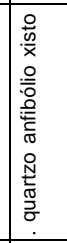 & 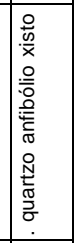 & 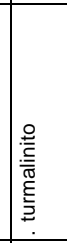 & 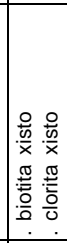 & & 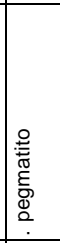 & 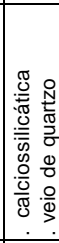 & 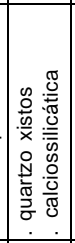 & 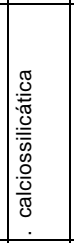 & 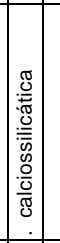 & & 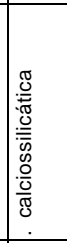 & \\
\hline 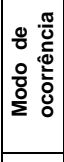 & 离. & $\frac{0}{\frac{\pi}{0}}$ & 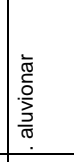 & 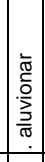 & 离 & 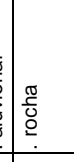 & & $\begin{array}{l}\frac{\pi}{2} \\
\underline{\underline{0}} \\
\underline{1}\end{array}$ & \begin{tabular}{|l}
$\frac{\pi}{5}$ \\
0 \\
0 \\
\end{tabular} & 离 & $\frac{\pi}{0}$ & \begin{tabular}{|l|}
$\frac{\pi}{\frac{\pi}{2}}$ \\
$\frac{0}{0}$ \\
\end{tabular} & 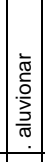 & 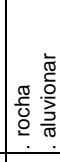 & 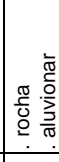 & 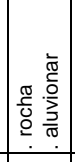 & 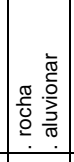 & 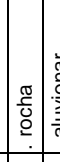 & 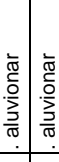 & 告 & 㐫 \\
\hline 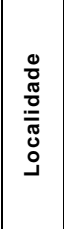 & 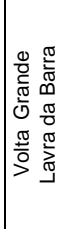 & 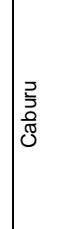 & 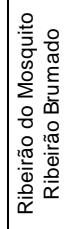 & 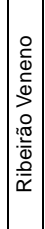 & 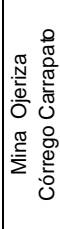 & 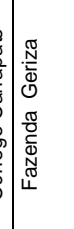 & \begin{tabular}{|l|} 
\\
$\frac{0}{\pi}$ \\
$\frac{\pi}{5}$ \\
$\frac{0}{0}$ \\
0 \\
$\frac{0}{2}$ \\
$\frac{\partial}{2}$ \\
\end{tabular} & 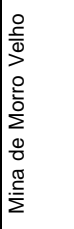 & 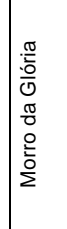 & 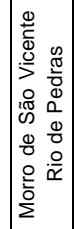 & 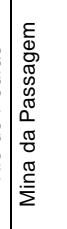 & 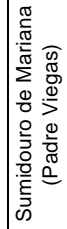 & 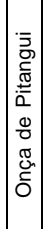 & 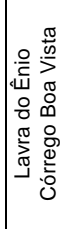 & 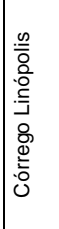 & 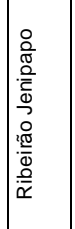 & 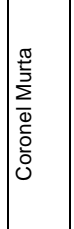 & 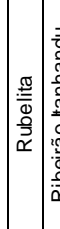 & 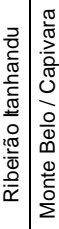 & 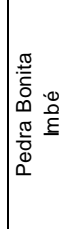 & 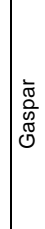 \\
\hline 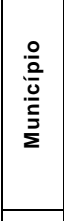 & 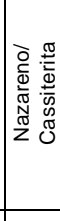 & 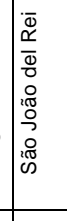 & 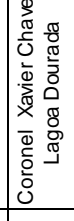 & 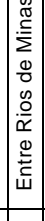 & & 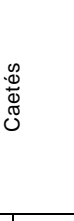 & & 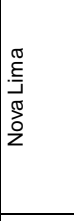 & 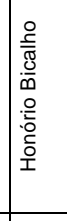 & 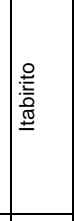 & 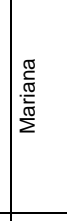 & $\mid \begin{array}{l}\frac{\tilde{\sigma}}{\sigma} \\
\frac{\tilde{\omega}}{\tilde{\omega}} \\
\frac{1}{2}\end{array}$ & & 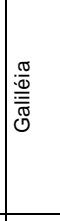 & 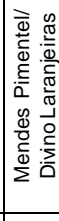 & | & $\mid$ & 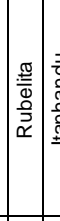 & 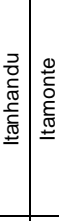 & 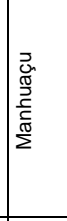 & $\frac{\bar{z}}{\bar{z}}$ \\
\hline $\begin{array}{l}\bar{\sigma} \\
\frac{\sigma}{\Phi} \\
\stackrel{5}{\Sigma}\end{array}$ & 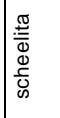 & 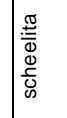 & 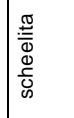 & 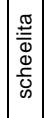 & 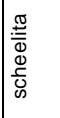 & & 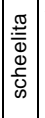 & 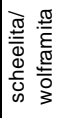 & 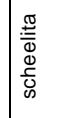 & 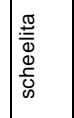 & 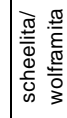 & 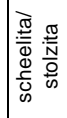 & 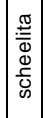 & 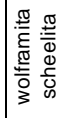 & 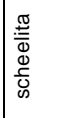 & 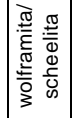 & 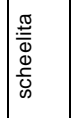 & 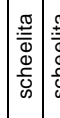 & 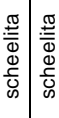 & 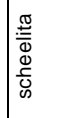 & 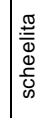 \\
\hline 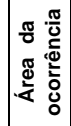 & - & - & - & - & $\sim$ & & $\sim$ & $\sim$ & N & $\sim$ & $\sim$ & $\sim$ & $\sim$ & $\infty$ & $\infty$ & $\sigma$ & $\nabla$ & +4 & مـ ما & 0 & 0 \\
\hline
\end{tabular}

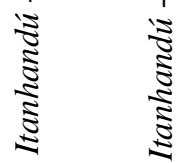

in in

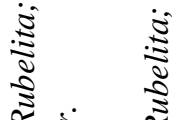

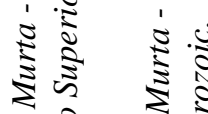

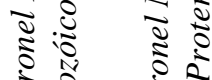

$\begin{array}{ccc}1 & 0 \\ 0 & 0 & 0 \\ 0 & 0 & 0 \\ 0 & 0 & 0\end{array}$

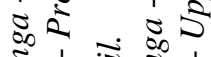

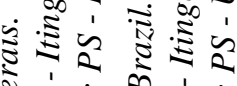

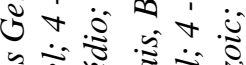

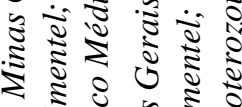

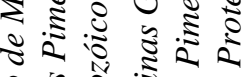

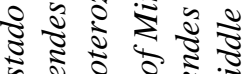

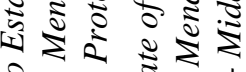

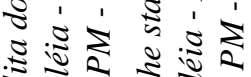

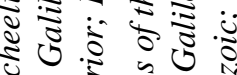

क

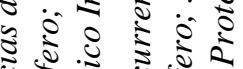

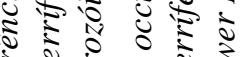

2.

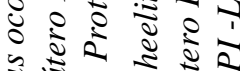

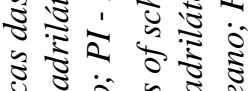

氝

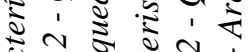

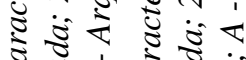

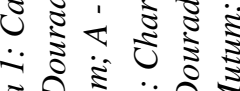

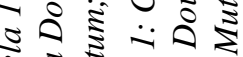

है

1
2
3

ป

ป ₹

is 6 \& 8

ปิ ริ

纯

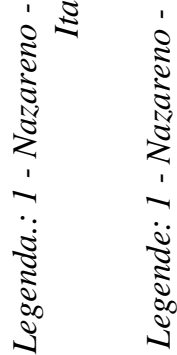


associadas, tais como biotita muscovita xistos, filitos, gonditos, turmalinitos e formação ferrífera bandada. Inicialmente, esse conjunto foi denominado de Greenstone Belt Barbacena (Pires 1978), embora outros autores sugerissem diferentes denominações, tais como Greenstone Belt Rio das Velhas-Lafaiete (Wernick 1981), Greenstone Belt Nova Lima-Lafaiete (Cordani \& Neves 1982), Greenstone Belt Rio das Mortes (Quemeneur 1987), Greenstone Belt ItumirimNazareno (Teixeira 1992).

A descoberta de minerais de tungstênio nas rochas vulcano-sedimentares do Greenstone Belt Barbacena foi, primeiramente, documentada por Santos \& Pereira (1983), que determinaram na região de Nazareno, a presença de scheelita nos concentrados de batéia e em xistos e rochas anfibolíticas. Esta foi observada disseminada, sob a forma de cristais xenoblásticos, às vezes porfiroblásticos, com côr de fluorescência brancaazulada, estando sempre associada à finas lentes de quartzo, concordantes com a foliação da rocha encaixante da mineralização.

Posteriormente, campanhas prospectivas por concentrados de bateia ampliaram a área de distribuição da scheelita, proporcionando a descoberta de novas ocorrências em outras localidades da região, como em Coronel Xavier Chaves e Resende Costa (Pereira 1985), em São João del Rei-Caburu (Pereira et al. 1989) e em Entre Rios de Minas.

A scheelita observada nas amostras da região de São João del Rei apresenta-se extremamente fina, com poucos grãos excedendo $2 \mathrm{~mm}$ e ocorre, predominan- temente, com cor de fluorescência branca-azulada forte, indicativa da ausência de molibdênio em sua estrutura. Análises químicas multielementares dos concentrados de bateia, por plasma de acoplamento indutivo (ICP) e Absorção Atômica (AA) para $\mathrm{Sn}, \mathrm{Pb}, \mathrm{Zn}$ e $\mathrm{Cu}$ e colorimetria para $\mathrm{W}$, apontaram, nesta região, valores anômalos em chumbo de até 14.000 ppm e em tungstênio de até 2.000 ppm (Pereira \& Ávila 1990). Os poucos afloramentos encontrados mineralizados foram classificados, petrograficamente, como anfibólio-gnaisses e anfibolitos, observando-se a scheelita em pequenos grãos, associados a finas vênulas quartzosas, semelhantemente, a região de Nazareno.

Segundo Pereira \& Ávila (1990), as mineralizações scheelitíferas desta área encontram-se distribuídas por uma extensa faixa de direção geral ENE, com cerca de 60 quilômetros de comprimento e 12 quilômetros de largura, estendendo-se desde o município de Nazareno até o de Lagoa Dourada, passando pelos arredores de São João del Rei e, provavelmente, interligando-se à região de Entre Rios de Minas (Figuras 2 e 3). Estes autores atribuem, ainda, caráter strata-bound e uma possível origem vulcano-sedimentar para as mineralizações de scheelita, em virtude, principalmente, da distribuição das ocorrências acompanhar o trend geral das rochas anfibolíticas, que foram correlacionadas por Pires et al. (1990) a unidade intermediária do Greenstone Belt Barbacena, cujas características químicas apontam para uma origem a partir de antigas rochas basálticas metamorfisadas (Barbosa 1985).

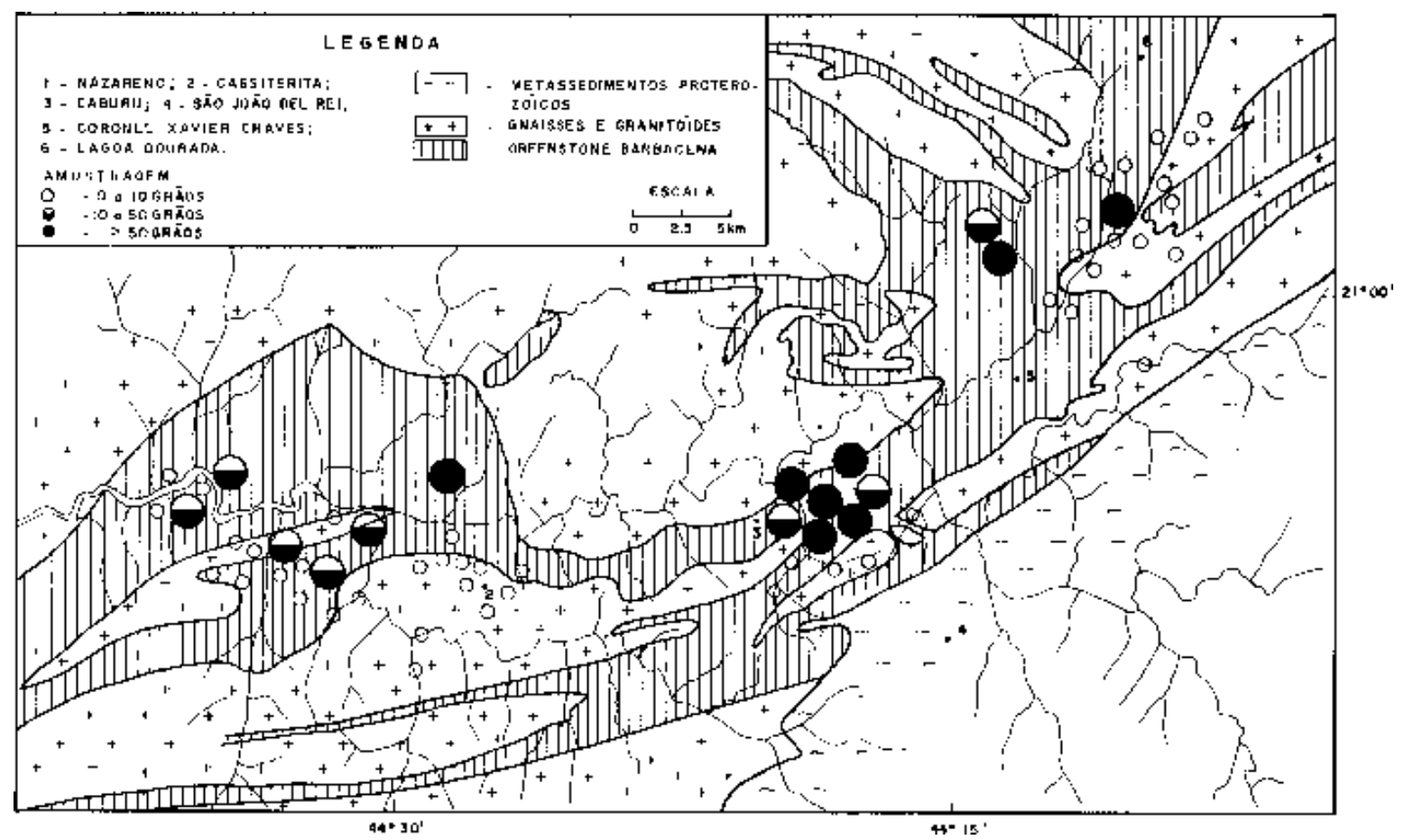

Figure 2: Distribuição das ocorrências de scheelita na área de Nazareno - São João del Rei - Lagoa Dourada (geologia segundo Pires et al. 1990).

Figure 2: Distribution of scheelite occurrences of the Nazareno - São João del Rei - Lagoa Dourada area (geology after Pires et al. 1990). 


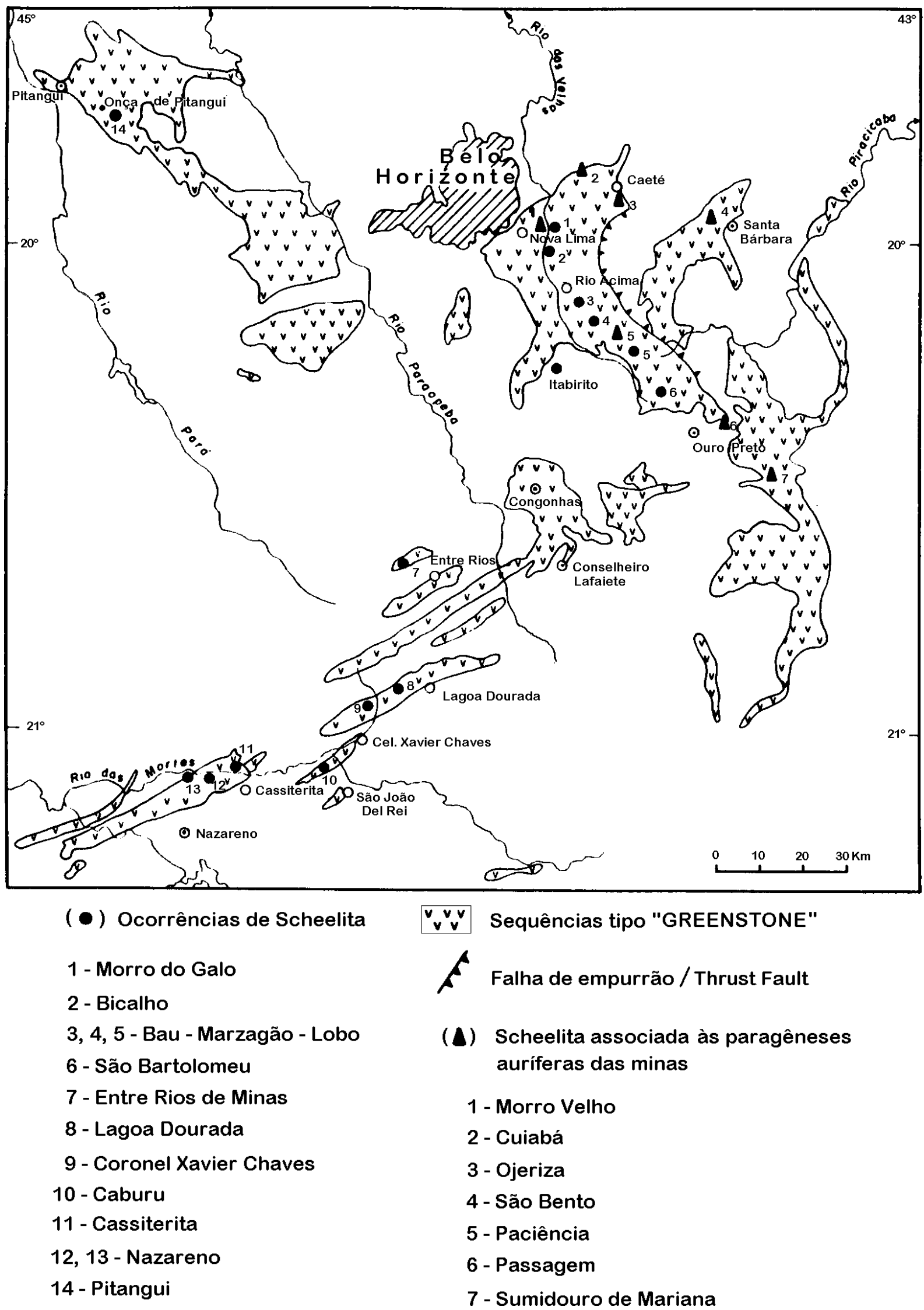

Figura 3: Mapa de distribuição das ocorrências de scheelita associadas às sequências greenstone da borda sul do cráton do São Francisco. Base geológica modificada do Mapa Metalogenético do Estado de Minas Gerais - 1:1000.000 (Vaz de Melo et al. 1994).

Figure 3: Distribution of scheelite occurrences associated with greenstone sequences at the southern border of the São Francisco Craton. Geological base modified after Metalogenetic Map of the state of Minas Gerais - 


\section{OCORRÊNCIAS DE SCHEELITA NA ÁREA DO QUADRILÁTERO FERRÍFERO}

O Quadrilátero Ferrífero compreende uma área de, aproximadamente, $7.000 \mathrm{~km}^{2}$, situando-se no centro sul do Estado de Minas Gerais. Essa região pode ser considerada como a de melhor conhecimento geológico do Brasil, destacando-se, nesta, mineralizações em ouro, ferro e manganês.

A partir do convênio firmado na década de 60 entre o DNPM-USGS, foram efetuados vários trabalhos de mapeamento geológico e levantamento das ocorrências minerais, que culminaram com a confecção de uma coluna estratigráfica regional, sumarizada por Dorr II (1969). Posteriormente, essa coluna foi sendo modificada por outros pesquisadores (Schorscher 1978; Ladeira 1988), mormente na parte que abrange as rochas vulcano-sedimentares de idade arqueana, pertencentes ao Supergrupo Rio das Velhas. Nessa sequência de rochas vulcano-sedimentares, denominada de Grupo Nova Lima, encontram-se as principais mineralizações de scheelita do Quadrilátero Ferrífero.

A primeira citação, quanto a presença de scheelita em Minas Gerais, deve-se a Graton (in Lindgren 1933) e foi relativa a um estudo sobre a mina de ouro de Morro Velho. Posteriormente, a mesma ocorrência foi citada por Ladeira (1988), que associou a scheelita à Formação Lapa Seca do Grupo Nova Lima, considerando-a como um mineral acessório da zona aurífera.

Guimarães \& Coelho (1944) caracterizaram a presença de scheelita, stolzita e raspita em uma extensa área mineralizada, localizada no distrito de Sumidouro de Mariana, atual Padre Viegas. A zona mineralizada constituída por veios de quartzo com scheelita, galena, arsenopirita, calcita e dolomita, apresenta-se encaixada em um filito clorítico, que corresponderia, segundo os autores, ao produto de alteração hidrotermal de rochas anfibolíticas e biotíticas, derivadas de antigos derrames básicos.

Magalhães \& Latorraca (1978) descreveram no
Município de Caetés a presença de scheelita associada a um leito de formação ferrífera bandada quartzo carbonatada, posicionada no topo de uma camada de xistos mineralizados em ouro, considerando a mesma como pertencente a seqüência vulcano-sedimentar do Greenstone Belt Rio das Velhas. Nessa mesma região, Pereira \& Santos (1983) determinaram várias novas ocorrências de scheelita em concentrados de bateia e em duas rochas mineralizadas (um clorita xisto e um xisto carbonoso/grafitoso) na antiga mina de ouro de Ojeriza. Na ocasião, os mesmos advogaram uma origem singenética-estratiforme para as ocorrências de scheelita de Caetés, correlacionando a zona mineralizada a um pacote de rochas vulcano-sedimentares, onde o vulcanismo apresentaria caráter variando de básico a intermediário.

Posteriormente, Pereira (1985) descreveu a presença de scheelita em concentrados de bateia nas proximidades de Raposos (Morro do Galo), Honório Bicalho (Morro da Glória), Rio de Pedras (minas de Paciência, Marzagão, Lobo e Maracujá) e na área de Onça do Pitanguí. A distribuição atual das ocorrências de scheelita da área do Quadrilátero Ferrífero pode ser melhor observada na Figura 3.

Pereira \& Santos (1990), utilizando o modelo evolutivo para zonas de cisalhamento auríferas, proposto por Bonnemaison (1986) e Bonnemaison \& Marcoux (1990), reinterpretaram a associação estibinita-scheelita, encontrada em algumas das principais minas de ouro do Quadrilátero Ferrífero, considerando estes minerais como pertencentes às paragêneses das zonas auríferas e integrantes das assinaturas geoquímicas de algumas destas minas (Tabela 2). Pereira (1994) apontou para o fato de que ao longo de toda a zona de cisalhamento de Paciência, definida por Scarpelli (1991), desde a mina de Morro Velho até a mina de Paciência em Rio de Pedras, a scheelita encontra-se sempre presente em estreita associação com as zonas auríferas identificadas.

\begin{tabular}{|c|c|c|}
\hline Depósito/Município & Mineralogia & Associação \\
\hline Morro Velho/Nova Lima & $\begin{array}{c}\text { ouro;arp;gal;est;sch; } \\
\text { mol;esf;calc }\end{array}$ & $\begin{array}{c}\text { Au-As-Pb-Sb-W- } \\
\text { Mo-Zn-Cu }\end{array}$ \\
\hline Cuiabá/Sabará & $\begin{array}{c}\text { ouro;arp;gal;sch;esf; } \\
\text { calc }\end{array}$ & $\begin{array}{c}\text { Au-As-Pb-W-Zn- } \\
\mathrm{Cu}\end{array}$ \\
\hline São Bento/Santa Bárbara & ouro;arp;sch;esf;calc & Au-As-W-Zn-Cu \\
\hline Paciência/ltabirito & ouro;arp;gal;est;sch & Au-As-Pb-Sb-W \\
\hline Juca Vieira/Caeté & ouro;arp;gal;est;sch & Au-As-Pb-Sb-W \\
\hline
\end{tabular}

Tabela 2: Principais elementos associados às mineralizações auríferas em zona de cisalhamento do Quadrilátero Ferrífero, Minas Gerais.

Legenda: arp - arsenopirita; est - estibinita; sch - scheelita; mol - molibdenita/galena; esf - esfarelita; calc - calcopirita

Table 2: Principal paragenesis associated with gold mineralization in shear zones within the Quadrilátero Ferrífero, Minas Gerais.

Legende: arp - arsenopyrite; est - stibnite; sch - scheelite; mol-molybdenite/galena; esf - sphalerite; calc - chalcopyrite 


\section{OCORRÊNCIA DE SCHEELITA DA ÁREA DE ITINGA-CORONEL MURTA-RUBELITA}

A área de Itinga-Coronel Murta-Rubelita, situada no nordeste do Estado de Minas Gerais, na região do Médio Rio Jequitinhonha, faz parte de um importante polo pegmatítico, produtor de água marinha, turmalina, cassiterita e minerais de lítio. Nessa área foram descritos dois tipos de mineralizações de tungstênio, onde no primeiro, a scheelita encontra-se presente em níveis de rochas calciossilicáticas nas localidades de Itinga, Coronel Murta e Rubelita (Pedrosa Soares et al. 1983; Pedrosa Soares 1984; Monteiro 1986; Monteiro et al. 1990), enquanto no segundo tipo, a scheelita ocorre associada a wolframita em veios de quartzo na região de Itinga (Pedrosa Soares 1984).

A primeira referência sobre a presença de minerais de tungstênio nas rochas do Médio Rio Jequitinhonha deve-se a Ferraz (1929), que faz uma breve citação quanto a existência de scheelita em Araçuaí. Posteriormente, Pedrosa Soares et al. (1983) relatam a presença de níveis calciossilicáticos mineralizados em scheelita nas regiões de Itinga e Coronel Murta, classificando-os, preliminarmente, como estratiformes. Nestes níveis, a scheelita ocorre associada a finos filetes quartzosos, concordantes com a orientação reliquiar da rocha ou em pequenos grãos disseminados, sem inclusões, formando uma matriz granoblástica com quartzo, diopsídio e andesina. Esses autores citam, ainda, a presença de um garimpo abandonado no baixo vale do ribeirão Jenipapo, a sudoeste de Itinga, onde a wolframita e a scheelita, esta com cor de fluorescência branco-azulada, foram encontradas associadas a veios de quartzo encaixados nos quartzo mica-xistos, atribuídos ao Grupo Macaúbas, que foi correlacionado por Almeida \& Litwinski (1984) ao Proterozóico Médio, e que segundo Correia Neves et al. (1982) teria sido formado ou retrabalhado durante o Evento Brasiliano. Posteriormente, essas rochas teriam sido cortadas por granitóides com idade de 516 M.a (Sá \& Kawashita 1976).

Segundo Pedrosa Soares (1984) a gênese das ocorrências de scheelita da região pode ser classificada como pertencente ao grupo sedimentar-metamórfico estratiforme, onde o tungstênio foi remobilizado durante o metamorfismo de antigos sedimentos pelíticos-psamíticos, cristalizando-se sob a forma de scheelita.

Monteiro (1986) subdivide as rochas calciossilicáticas da região de Rubelita em diopsídicas e anfibolíticas, onde as primeiras apresentam predomínio de diopsídio e epidoto em relação ao anfibólio e encontram-se mineralizadas. Monteiro et al. (1990) propõem um modelo epigenético para a formação da mineralização, onde o tungstênio seria oriundo de seqüências sedimentares ou vulcano-sedimentares, que sofreram um processo de anatexia, gerando fusões graníticas. Durante a cristalização dessas fusões, o W seria incorporado às muscovitas nas zonas de cúpula ou se precipitaria nas rochas calciossilicáticas, a partir da interação do fluído mineralizante com o Ca proveniente de minerais, tais como plagioclásio, epidoto e diopsídio.

\section{OCORRÊNCIA DE SCHEELITA DA ÁREA DE GALILÉIA-MENDES PIMENTEL}

A área de Galiléia-Mendes Pimentel encontra-se localizada na porção nordeste do Estado de Minas Gerais, situando-se nas proximidades da cidade de Governador Valadares. Essa região faz parte da Província Pegmatítica Oriental Brasileira, que abrange além da região de Governador Valadares, o Município de Teófilo Otoni, constituindo-se, no passado, como o mais importante centro produtor de gemas do Brasil. Geologicamente, a região pertence ao Grupo São Tomé (Silva et al. 1987) e encontra-se representada por um pacote de mica xistos, informalmente denominados por Barbosa et al., (1966) de xistos São Tomé, que foram correlacionados por Inda et al. (1984) ao Arqueano. Esse conjunto apresenta-se cortado por biotita granitóides do tipo Galiléia, responsáveis pela formação dos pegmatitos potadores de gemas (Moura et al. 1978) e com idades $\mathrm{Rb} / \mathrm{Sr}$ em rocha total de $550 \pm 20$ M.a (Campos Neto \& Figueiredo 1995).

A primeira referência a minerais de tungstênio nessa área deve-se a Cassedanne \& Cassedanne (1978), que descreveram a presença de wolframita associada ao pegmatito do Ênio, localizado próximo a cidade de Galiléia. Posteriormente, Cassedanne \& Pereira (1982a) e Pereira \& Neves (1982) registraram a presença de scheelita em concentrados de bateia na região de Galiléia-Mendes Pimentel. Esta apresentava-se predominantemente fina $(<0,35 \mathrm{~mm})$, com raros grãos grossos (1 a $3 \mathrm{~mm}$ ), e cor de fluorescência brancaazulada.

Cassedanne \& Pereira (1982b) observaram que, no alto ribeirão Laranjeiras e no córrego Linópolis, as concentrações de scheelita encontradas nas áreas de afloramento dos mica xistos associavam-se à rochas silicosas, acinzentadas, variavelmente listradas e caracterizadas pela presença de anfibólio, turmalina e granada. Estes tecem considerações, ainda, quanto a provável gênese das mineralizações scheelitíferas, caracterizando-as como de origem vulcano-sedimentar, sugerindo um modelo, no qual o tungstênio estaria associado a precipitados silicosos, depositados em ambiente marinho, que seriam recobertos por material vulcânico. Essas rochas seriam, posteriormente, metamorfisadas e se transformariam em xistos com intercalações silicosas ricas em tungstênio. Em seguida, esse elemento seria remobilizado, através do calor fornecido pelos corpos de granitóides e drenado para o contato dos xistos com as rochas intrusivas ou para veios de quartzo, que cortam todo o conjunto.

\section{OCORRÊNCIA DE SCHEELITA DA ÁREA DE ITAMONTE-ITANHANDU}

A porção sudoeste do Estado de Minas Gerais, onde encontram-se situados os municípios de Itamonte e Itanhandu, corresponde a uma região, cuja geologia ainda é relativamente mal conhecida. Os litotipos nela 
encontrados compreendem, basicamente, rochas metassedimentares, representadas por biotita-granada gnaisses, finamente laminados, mica xistos, cianitasillimanita xistos e quartzitos, além de rochas calciossilicáticas e gonditos. Trabalhos mais recentes, de cunho regional, agrupam as rochas que aí ocorrem ao Ciclo Deposicional Andrelândia (Junho 1995). Esse conjunto encontra-se intrudido por corpos de leucogranitos esbranquiçados com características tardi a pós tectônicas, representados pelos Granitos Capivara e Itanhandú (denominações informais), que se apresentam fracamente mineralizados em cassiterita e columbita-tantalita, sendo o último corpo correlacionado à Suíte Intrusiva Três Córregos, pressuposta por Machado Filho et al. (1983) como de idade Proterozóica Superior.

Os leucogranitos foram considerados por Junho (1995) como granitóides do tipo $S$ oriundos da fusão parcial de arenitos feldspáticos. Normalmente encontram-se enriquecidos em boro, podendo às vezes apresentar fácies localizadas, extremamente enriquecidas em turmalina preta, de tal sorte que a rocha pode ser considerada como um turmalina granito (Pereira et al. 1994).

A presença de scheelita na região foi verificada através de um levantamento de caráter regional utilizando-se concentrados de bateia. Esta encontra-se, quase sempre, associada à cassiterita, apontando para uma possível relação paragenética entre esses dois minerais, presumivelmente, associada a paragênese das mineralizações estaníferas em zonas de graisens.

\section{OCORRÊNCIA DE SCHEELITA DE RIO MANHUAÇU-MUTUM}

A região do Rio Manhuaçu-Mutum encontra-se compreendida no Complexo Pocrane (Silva et al. 1987), fazendo parte da Província Pegmatítica Oriental Brasileira. Litologicamente, a região é representado por biotita gnaisses, biotita-granada gnaisses e hornblendabiotita gnaisses com xistos associados, que se encontram deformados ductilmente. Os quartzitos grossos são geralmente friáveis, muscovíticos e foliados, enquanto os tipos finos são compactos e placóides. Os granitóides compreendem tipos tonalíticos, graníticos, granodioríticos e pequenos aplitos variando desde finos a porfiróides, foliados ou não e atribuídos ao Proterozóico Superior (Silva et al. 1987). Plugs de rochas ultrabásicas duníticas e harzburgíticas serpentinizadas também ocorrem na região (Scabora \& Penha 1992).

Nessa região foi descoberta a ocorrência de scheelita e barita de Pedra Bonita/Imbé, cuja provável fonte corresponde às lentes estiradas de rochas calciossilicáticas contidas nos granitóides de Imbé. Essas lentes calciossilicáticas que contém scheelita, barita, granada, epidoto, quartzo, anfibólios e piroxênios são interpretadas como produtos de metamorfismo de contato de granitóides em rochas carbonáticas, estando o conjunto cisalhado heterogeneamente (Scabora \& Penha 1992).
As ocorrências aluvionares de scheelita da área de Mutum devem, provavelmente, estar associadas a um contexto geológico bastante semelhante ao da região de Imbé, ou seja, presente em lentes de rochas calciossilicáticas associadas às rochas granitóides locais. Nessa área determinou-se a presença de uma pequena apófise de um leucogranito mineralizado somente em molibdenita. Apesar da presença desse metal na área, os grãos de scheelita observados nos concentrados de bateia apresentam cor de fluorescência branca- azulada, o que denota a ausência de molibdênio na sua estrutura (Pereira et al. 1996).

\section{DISCUSSÕES}

Análises químicas multielementares por ICP, AA e colorimetria de concentrados de bateia da região de São João del Rei-Caburu permitiram que se estabelecesse a presença de duas associações de elementos bastante singulares:

- Associação Sn-Nb-Ta-La-Y-Ce-Zr que foi correlacionada aos corpos pegmatíticos que cortam todas as rochas do embasamento;

- Associação Pb-W-Zn-Ag-(Cu) que foi correlacionada às rochas mineralizadas que compõem a sequência básica do pacote vulcano-sedimentar do Greenstone Belt Barbacena.

O primeiro tipo de associação é bastante comum em províncias pegmatíticas estaníferas, onde os principais minerais dos pegmatitos correspondem à cassiterita e columbita-tantalita. Monazita, xenotímio e zircão, por sua vez, podem ocorrer tanto relacionados aos corpos pegmatíticos, quanto às rochas encaixantes.

O segundo tipo de associação apresenta-se em um contexto semelhante ao descrito para as mineralizações de $\mathrm{Pb}-\mathrm{W}-\mathrm{Zn}-\mathrm{Ga}$ do cinturão arqueano Malene da Groenlândia (Appel 1986) e Pb-Ag-Zn-W do Bloco Broken Hill na Austrália (Barnes 1983). Caso essa correlação possa ser efetivamente estabelecida, a perspectiva metalogenética para a região em questão fica ampliada e, à semelhança da área de Broken Hill, depósitos de pequeno porte mineralizados em scheelita, e até mesmo sulfetos $(\mathrm{Pb})$, poderão ser encontrados. A ressalva para esta proposição deve-se ao fato de que a caracterização das associações presentes em Malene e Broken Hill foi obtida a partir de análises químicas de rochas, enquanto que a do Greenstone Belt Barbacena foi estabelecida a partir de análises de concentrados de bateia.

A relação $\mathrm{Au}-\mathrm{W}$ já foi descrita em diversas partes do mundo (Anhauesser 1976; Foster 1977; Smeth et al. 1985; Robert \& Brown 1986; Beljavsky \& Born 1989), sendo a scheelita sempre apontada como um mineral acessório das zonas auríferas (Overstreete \& Bell in Boyle 1979; Pereira 1985; Rao et al. 1989). Suszczynski (1975), analisando a presença de scheelita no Quadrilátero Ferrífero, concluiu que as raras ocorrências desse mineral na região representariam, apenas, um marco metalogenético para os depósitos auríferos. A constante presença da scheelita nas 
paragêneses minerais das principais minas de ouro do Quadrilátero Ferrífero (Morro Velho, Cuiabá, São Bento, Paciência, Bicalho, Ojeriza, entre outras), atualmente consideradas como relacionadas ao modelo de mineralizações auríferas associadas às zonas de cisalhamento (Scarpelli 1991), apontam para a tendência deste mineral ser considerado como um dos mais significativos traçadores para as mineralizações auríferas associadas a zonas de cisalhamento em ambientes do tipo Greenstone Belts.

Apesar da existências de duas teorias distintas (singenética-estratiforme e epigenética) para explicar as mineralizações da área de Itinga-Coronel MurtaRubelita, a proposta melhor desenvolvida é epigenética (Monteiro 1986). Dessa forma, a scheelita encontrada no Médio Jequitinhonha relaciona-se a processos de remobilização do tungstênio contido na seqüência sedimentar ou vulcano-metassedimentar. O calor gerado pelas rochas graníticas intrusivas ocasionaria a lixiviação do $\mathrm{W}$ da rocha encaixante, incorporando-o ao sistema ígneo. Posteriormente, a partir da cristalização desse magma, o tungstênio entraria na estrutura das muscovitas na zona de cúpula ou cristalizaria como scheelita nos níveis calciossilicáticos, devido, principalmente, à elevação do $\mathrm{pH}$ do fluído e interação deste com o Ca derivado dos minerais das rochas calciossilicáticas (Krauskopf \& Evans 1970).

$\mathrm{Na}$ área de Galiléia-Mendes Pimentel, no Médio Rio Doce, o mecanismo sugerido por Cassedanne \& Pereira (1982a; 1982b) para a incorporação do tungstênio aos finos níveis de sedimentos (em um modelo singenético) seria semelhante ao que gera os precipitados de sílica e tungstênio da área de Taupo na Nova Zelândia. As manifestações tonalíticas e granodioríticas locais se encarregariam de fornecer o calor necessário para a cristalização da scheelita nos níveis calciossilicáticos e de drenar parte do tungstênio da seqüência vulcano-sedimentar, propiciando a cristalização da scheelita nos veios de quartzo e wolframita nos pegmatitos, em um modelo epigenético, em parte semelhante ao proposto por Monteiro et al., (1990) para a região de Itinga-Coronel Murta-Rubelita.

Na área de Itamonte-Itanhandu, no sudoeste do Estado de Minas Gerais, a scheelita encontra-se, presumivelmente, relacionada às paragêneses das mineralizações estaníferas, localizadas nas zonas de cúpulas geradas pelos Granitos Capivari e Itanhandu, em um modelo do tipo greisen. Shcherba et al. (in Stemprok 1987) relacionam a scheelita como um dos constituintes raros dos greisens. As mineralizações de cassiteritawolframita (molibdenita) de Itapeva-Rio Branco (Goraieb et al. 1988), Sorocaba (Saldanha \& Franco 1946), Serra de São Francisco (Barbosa \& Maciel 1951) e Itupeva (Saldanha 1946), todos aflorantes no Estado de São Paulo, apontam para a tendência mineralizadora em metais raros nos plutonitos pós tectônicos pertencentes à Suíte Intrusiva Três Córregos. Desta forma, admite-se que a associação scheelita-cassiterita-columbita-tantalita, encontrada nas amostras de concentrados de batéia na área de Itamonte-Itanhandu, estaria relacionada aos corpos leucograníticos supracitados, de caráter tardi a póstectônicos, pertencentes a Suíte Intrusiva Três Córregos.

Nas áreas de Pedra Bonita/Imbé no Rio Manhuaçu e em Mutum, a presença de scheelita associada às lentes de rochas calciossilicáticas, encontradas dentro de um domínio composto por granitóides, aponta para um modelo do tipo reaction skarns para essas mineralizações de uma forma semelhante à proposta por Skaarup (1974) para as ocorrências de scheelita da área de Bindal na Noruega.

\section{MODELOS METALOGENÉTICOS}

De um modo geral, nas áreas de Nazareno-São João del Rei-Lagoa Dourada, do Quadrilátero Ferrífero e de Galiléia-Mendes Pimentel, a scheelita teria a origem vulcanogênica-exalativa submarina, onde o $\mathrm{W}$ seria lixiviado das pilhas vucânicas e sedimentares préexistentes, através da percolação de flúidos hidrotermais senso lato (soluções salinas aquecidas). A precipitação do $\mathrm{W}$ com os sedimentos químicos na interface rocha vulcânica-sedimento (em um modelo singenético) ocorreria, principalmente, durante o período de quiescência do vulcanismo (Plimer 1980; Fulp \& Renshaw 1985; Appel 1986). Posteriormente durante o metamorfismo dessa seqüência de rochas, o aumento da temperatura e da pressão provocaria reações de desidratação e descarbonatização, liberando voláteis, água e gás carbônico, que se combinariam com o W, formando complexos clorídricos passíveis de serem transportados (Foster 1977) e depositados conjuntamente com o quartzo (em um modelo epigenético), em um ambiente onde o $\mathrm{pH}$ fosse superior a 7.2, através da neutralização da solução ácida (Maucher 1976). No caso específico da área do Quadrilátero Ferrífero, o tungstênio sofreria ainda uma nova remobilização, juntamente com o ouro, durante as fases de evolução das zonas de cisalhamento presentes, de acordo com o modelo de shear zones auríferas proposto por Bonnemaison \& Marcoux (1990).

O modelo para as ocorrências de Itinga-Coronel Murta-Rubelita e, possivelmente, Itamonte-Itanhandu, envolve um forte componente epigenético, onde o tungstênio seria proveniente da deposição de antigos níveis pelíticos-psamíticos ou vulcano-sedimentares (origem singenética), que, posteriormente, ao sofrerem um processo de anatexia, incorporariam o $\mathrm{W}$ ao magma granítico gerado (origem epigenética), precipitando-o nas zonas de reação com as rochas calciossilicáticas, a partir da diminuição do $\mathrm{pH}$ do flúido e liberação de cálcio, ou então, em zonas greisenizadas.

O modelo da região do Rio Manhuaçu-Mutum envolveria a precipitação de finos níveis de sedimentos (margas), que ao serem metamorfisados proporcionariam a formação de rochas calciossilicáticas mineralizadas em scheelita (reaction skarns). Estas rochas foram cortadas por corpos de composição granítica, estando presente nos mesmos como xenólitos e/ou roof pendants. 


\section{CONCLUSÕES}

O Estado de Minas Gerais apresenta seis áreas précambrianas mineralizadas em scheelita, sendo que quatro dessas podem a priori, ser correlacionadas a seqüências vulcano-sedimentares, que foram remobilizadas, em maior ou menor escala, por processos metamórficos, de cisalhamento ou associados ao emplacement de corpos de granitóides.

A distribuição das ocorrências de scheelita do Estado de Minas Gerais pode ser subdividida em:

- Área de Nazareno-São João del Rei-Lagoa Dourada, onde as mineralizações de scheelita possuem carater strata bound e encontram-se acompanhando uma faixa de rochas vulcano-sedimentares arqueanas, atualmente representadas por xistos verdes, anfibólio xistos, anfibolitos e anfibólio gnaisses, intercalados com metassedimentos, turmalinitos, cherts e rochas calciossilicáticas, pertencentes à seqüência vulcano sedimentar do Greenstone Belt Barbacena;

- Área do Quadrilátero Ferrífero, onde as mineralizações de scheelita encontram-se presentes nos litótipos vulcânicos metabásicos cisalhados de idade arqueana do Grupo Nova Lima, pertencente ao Greenstone Belt Rio das Velhas e apresentam-se associadas às paragêneses das mineralizações auríferas em zonas de cisalhamento, sendo a scheelita considerada como um possível guia prospectivo para os depósitos de ouro;

- Área de Itinga-Coronel Murta-Rubelita, no Médio Rio Jequitinhonha, onde o modelo mais aceito para as ocorrências de scheelita envolve uma origem epigenética, onde o tungstênio seria oriundo de seqüências sedimentares ou níveis vulcano-sedimentares, associados ao Grupo Macaúbas, que foram fundidos, ocasionando a formação de um magma granítico enriquecido nesse elemento, que interagiria com níveis calciossilicáticos, precipitando a scheelita;

- Área de Galiléia-Mendes Pimentel no Médio Rio Doce, onde a scheelita está relacionada aos xistos São Tomé, considerados como arqueanos, que representam antigos níveis vulcano-sedimentares e aos veios de quartzo mobilizados, em virtude do calor gerado pelas intrusões das rochas graníticas do Proterozóico Superior;

- Área de Itamonte-Itanhandu no sudoeste de Minas Gerais, onde a scheelita encontra-se, presumivelmente, associada às paragêneses das mineralizações estaníferas em zonas de greisens relacionadas às intrusões leucograníticas (granitos Capivara e Itanhandu) de caráter tardi a pós-tectônicas, da Suíte Intrusiva Três Córregos, do Proterozóico Superior.

- Área do Rio Manhuaçú-Mutum no nordeste de Minas Gerais, onde a scheelita encontra-se relacionada a lentes de rochas calciossilicáticas (reaction skarns), contidas dentro de um domínio composto, predominantemente, de corpos de granitóides associados ao Proterozóico Superior.

\section{AGRADECIMENTOS}

Este trabalho foi desenvolvido com o apoio financeiro da Fundação Universitária José Bonifácio. Agradecemos aos professores Elson Paiva Oliveira da Universidade de Campinas e Claudio Porto da Universidade Federal do Rio de Janeiro pela revisão, sugestões e discussões referentes ao texto, ao professor Joel Gomes Valença da Universidade Federal do Rio de Janeiro pela leitura e correção do abstract e ao Laboratório de Análises Minerais da Companhia de Pesquisa de Recursos Minerais pelas determinações de tungstênio por colorimetria.

\section{BIBLIOGRAFIA}

ALMEIDA, F.F.M. 1977. O Cráton do São Francisco. Rev. Bras. Geoc., 7 (4):349-364.

ALMEIDA, F.F.M. \& LITWINSKI, N. 1984. Província Mantiqueira. In: ALMEIDA, F.F.M. \& HASUI, Y. eds. O PreCambriano do Brasil. Brasil, Edgard Blücher. p. 282-369.

ANHAUESSER, C.R. 1976. The nature and distribution of archean gold mineralization in Southern Africa. Min. Sci. Eng., 8:4684.

APPEL, P.W.U. 1986. Strata bound scheelite in the Archean Malene supracrustal belt, West Greenland. Mineral. Deposita, 21:207-215.

ÁVILA, C.A. 1992. Geologia, petrografia e geoquímica das rochas plutônicas Pré-Cambrianas (Unidade Metadiorítica Ibitutinga e Unidade Metatrondhjemítica Caburu), intrusivas nas rochas do Greenstone Belt Barbacena, São João del Rei, Minas Gerais. Rio de Janeiro. 265p. (Dissertação de Mestrado, Universidade Federal do Rio de Janeiro).

ÁVILA, C.A. \& VALENÇA, J.G. 1992. Estratigrafia e cronologia relativa dos principais tipos litológicos do embasamento da região de São João Del Rei, Minas Gerais. In: CONGR. BRAS. GEOL., 37. São Paulo, 1992. Bol. Res. Exp...São Paulo, SBG. v.2, p. $136-137$

BARBOSA, A.F. \& MACIEL, P. 1951. Mineralização de estanho e tungstênio na Serra de São Francisco, Estado de São Paulo. Rev. Eng. Min. Metal., XVI (92):145-150.

BARBOSA, M.I.M. 1985. Geoquímica das faixas máficasultramáficas, plutonitos e migmatitos do "Greenstone Belt" Barbacena, na região de Conselheiro Lafaiete $(M G)$. Rio de Janeiro. 227p. (Dissertação de Mestrado, Universidade Federal do Rio de Janeiro).

BARBOSA, A.L.M; SAD, J.G.; TORRES, N.; MELO, M.T.V. 1966. Descrição do mapa geológico preliminar do médio Rio Doce. Rio de Janeiro, SBG. 10 p. (Boletim 2).

BARNES, R. G. 1983. Stratiform and stratabound tungsten mineralisation in the Broken Hill Block, N.S.W. J. Geol. S. Austr., 30:225-239.

BELJAVSKIS, P. \& BORN, H. 1989. Estudos litogeoquímicos na ocorrência de ouro Tapera Grande - Guarulhos - SP. In: SIMP. GEOL. SUDESTE, 1. Rio de Janeiro, 1989. Bol. Res....Rio de Janeiro, SBG-RJ. p. 87-88.

BONNEMAISON, M. 1986. Les "filons de quartz aurifère": un cas particulier de shear zone aurifère. Chron. Rech. Min. 482:55-65

BONNEMAISON, M. \& MARCOUX, E. 1990. Auriferous mineralization in some shear-zones: A three-stage model of metallogenesis. Mineral. Deposita, 25:96-104.

BOYLE, R.W. 1979.The geochemistry of gold and its deposits (together with a chapter on geochemical prosppecting for the element). Geol. Surv. of Can., Bull. 280: 1-584p.

CAMPOS NETO, M.C \& FIGUEIREDO, M.C.H. 1995. The Rio Doce Orogeny, Southeastern Brazil. J. South Amer. Earth Sci., 8(2):143-162;

CASSEDANNE, J.P \& CASSEDANNE, J.O. 1978. Présence de wolframite dans une pegmatite près de Galiléia (MG). An. Acad. Bras. Ci., 50 (1):89-93.

CASSEDANNE, J.P \& PEREIRA, R.M. 1982a. Découverte de scheelite dans la Province Pegmatitique Orientale Brésilienne. An. Acad. Bras. Ci., 54(2):413-417.

CASSEDANNE, J.P \& PEREIRA, R.M.1982b. Tipologia possível das ocorrências de scheelita da Província Pegmatítica Oriental Brasileira à luz dos depósitos tungsteníferos de San Luis 
(Argentina). Min. Metal., 436:22-27.

CORDANI, U.G. \& NEVES, B.B.B. 1982. The geologic evolution of South America during the Archaean and Early Proterozoic. Rev. Bras. Geoc., 12(1-3):78-88.

CORREIA NEVES, J.M.; MONTEIRO, R.L.B.P.; PEDROSASOARES, A.C. 1982. Granitóides da região de Coronel Murta, Minas Gerais. In: CONGR. LAT. AMER. GEOL., 5. Buenos Aires, 1982. Actas...Buenos Aires, v.2, p. 133-146.

DORR II, J. V.N.N. 1969. Physiographic, stratigraphic and structural development of Quadrilatero Ferrifero, Minas Gerais, Brazil. Geol. Survey Prof. Paper., 641(A):1-110.

FERRAZ, L.C. 1929. Compendio dos mineraes do Brasil. Imprensa Nacional, Rio de Janeiro.

FOSTER, R. P., 1977. Solubility of scheelite in hydrothermal chloride solutions. Chem. Geol., 20:27-43.

FULP, M.S. \& RENSHAW, J.L. 1985 Volcanogenic-exhalative tungsten mineralization of Proterozoic age near Santa Fe, New Mexico, and implications for exploration. Geology, 13(1):6669.

GORAIEB, C.L.; OLIVEIRA, M.C.B; MELLO, I.S.C.; SILVA, R.B., 1988. As mineralizações estano-tungsteníferas do granito Correas (SP). In: CONGR. LAT. AMER. GEOL, 7. Belém, 1988. Anais... Belém, SBG.v.1, p. 154-172.

GUIMARÃES, D \& COELHO, I.S., 1944. Nota preliminar sobre as jazidas de minerais tugstênicos em Sumidouro, Mariana Minas Gerais. Rio de Janeiro, DNPM/DFPM. p. 13-42 (Avulso $60)$.

INDA, H.A.V.; SCHORSCHER, H.D.; DARDENNE, M.A.; SCHOBBENHAUS, C.; HARALYI, N.L.E.; BRANCO, P.C.A.; RAMALHO, R. 1984. O Craton do São Francisco e a faixa de dobramentos Araçuaí. In: SCHOBBENHAUS, C.; CAMPOS, D.A.; DERZE, G.R.; ASMUS, H.E.eds. Geologia do Brasil. Brasília, DNPM. p.193-248.

JUNHO, M.C.B. 1995. Leucogranites and related migmatites, southern Minas Gerais and southwestern Rio de Janeiro states, Brazil. An. Acad. brasil. Ci., 67(4):497-515.

KRAUSKOPF, K.B. \& EVANS, H.T. 1970. Tungsten. In: WEDEPOHL, K.H. ed. Handbook of Geochemistry. Berlin, Springer-Verlag. Cap. 74, p.74 A1-74 O4.

LADEIRA, E.A. 1988. Metalogenia dos depósitos de ouro do Quadrilátero Ferrífero, Minas Gerais. In: Schobenhaus, C.\& Coelho, C.E.S. Principais depósitos minerais do Brasil. (metais básicos nãoferrosos, ouro e alumínio) DNPM/CVRD. v. 3. p. 301-375

LINDGREN, W. 1933. Mineral Deposits. 1 ed. New York, McGraw-Hill. 930 p.

MAGALHÃES, C. \& LATORRACA, F., 1978. Prospecção de ouro em Caeté, MG. In: CONGR. BRAS. GEOL., 30. Recife, 1978. Anais...Recife, SBG. v. 4, p. 1827-1835.

MACHADO FILHO, L; RIBEIRO, M.W. GONZALES, S.R. SCHENINI, C.A.; NETO, A.S.; PALMEIRA, R.C.B.; PIRES, J.L.; TEIXEIRA, W.; CASTRO, H.E.F. 1983. Projeto RADAMBRASIL. Folhas SF 23/24 Rio de Janeiro/Vitória. Rio de Janeiro, v.32, p.27-304.

MAUCHER, A.,1976. The strata-bound cinnabar-stibnite-scheelite deposits (discussed with examples from the Mediterranean region). In: Wolf, K.H .ed. Handbook of strata-bound and stratiform ore deposits. Amsterdam, Elsevier. v. 7, p. 477503.

MONTEIRO, R.L.B.P. 1986. As mineralizações de tungstênio no médio vale do Jequitinhonha, NE de Minas Gerais, Brasil. Brasília. 236p. (Dissertação de mestrado, Universidade de Brasília).

MONTEIRO, R.L.B.P.; LEONARDOS, O.H.; CORREIA-NEVES, J.M. 1990. An epigenetic origin for the new scheelite and wolframite occurrences in the middle jequitinhonha valley, Minas Gerais, Brazil. Rev. Bras. Geoc., 20(1-4):68-74.

MOURA, O.J.M.; FANTON, J.J.; ARIOLI, E.A. 1978. Geologia da região de Galiléia-Mendes Pimentel - Minas Gerais. In: CONGR. BRASIL. GEOL.,30. Recife, 1978. Anais... Recife, SBG. v.1, p. 26-37.

PEDROSA SOARES, A.C. 1984. Metamorfismo, granitogênese e mineralizações associadas na região de Coronel Murta, NE de Minas Gerais, Brasil. Brasília, 171p. (Dissertação de Mestrado, Universidade de Brasília).

PEDROSA SOARES, A.C.; COSTA, A.G.; CORREIA NEVES,
J.M. 1983. A mineração de scheelita nas rochas calcossilicáticas do Médio Jequitinhonha - MG. In: SIMP. GEOL. MINAS GERAIS, 2. Belo Horizonte, 1983. Anais...Belo Horizonte, SBG. v.1, p. 297-305.

PEREIRA, R.M. 1985. Metalogenia previsional da scheelitaestibinita na região do Cráton do São Francisco. Relatório $\mathrm{CNPq} / \mathrm{n} \quad 160.407756$

PEREIRA, R.M. 1994. Os alinhamentos mineiros do Quadrilátero Ferrífero: uma premissa prospectiva. In: CONGR. BRAS. GEOL., 38. Camboriú, 1994. Bol. Res. Exp... Camboriú, SBG. v.2, p. $122-123$.

PEREIRA, R.M. \& ÁVILA, C.A. 1990. Distribuição da scheelita ao longo da faixa anfibolítica do "greenstone belt" Barbacena, Minas Gerais. In: CONGR. BRAS. GEOL, 36. Natal, 1988. Anais ...Natal, SBG. v. 3, p. 1232-1240.

PEREIRA, R.M.; ÁVILA, C.A.; ROIG, H.L. 1996. Registro sobre a presença de molibdenita em Mutum, MG. In: CONGR. BRAS. GEOL., 39. Salvador, 1996. Anais...Salvador, SBG. V. 3, p. 173-175.

PEREIRA, R.M; ÁVILA, C.A; SANTOS, R A ; FERREIRA, E.A. 1989. Mineralizações de scheelita nas rochas anfibolíticas do greenstone Barbacena, na área de Nazareno-São João del ReiLagoa Dourada, MG. In: SIMP. GEOL. MINAS GERAIS, 5. Belo Horizonte, 1989. Anais ...Belo Horizonte, SBG. v.1, p. 90-93.

PEREIRA, R.M. \& NEVES, J.L.P. 1982. Mineralizações scheelitíferas na região do Meio Rio Doce, Minas Gerais, Brasil. In: CONGR. LAT. AMER. GEOL., 5. Buenos Aires, 1982. Anais...Buenos Aires. v.2, p.577-562.

PEREIRA, R.M \& SANTOS, R.A. 1983. A ocorrência de scheelita estratiforme de Caeté, MG: base de uma nova interpretação metalogenética para os índices de W, Sb, $\mathrm{Hg}$ do Quadrilátero Ferrífero. Min. Metal., 450:38-42.

PEREIRA, R.M \& SANTOS, R.A. 1990. A scheelita como guia para a prospecção de ouro em "shear zones"nas sequências vulcano-sedimentares do tipo "greenstone belts". Min. Metal., 516:43-44.

PEREIRA, R.M \& SANTOS, R.A. 1992. A scheelita como um mineral traçador das zonas de cisalhamento auríferas: o exemplo do Quadrilátero Ferrífero e do Greenstone Belt do Rio Itapicuru. Rev. Esc. Min. Ouro Preto, 45(1-2):133-134.

PEREIRA, R.M.; SANTOS, R.A.A.; NEVES, J.L.P. 1994 Prospecção à bateia na borda oriental da região sudeste do Brasil: primeiros resultados. In: CONGR. BRAS. GEOL, 38. Camboriú, 1994. Bol. Res. Exp....Camboriú, SBG. v.2, p.197198.

PIRES, F.R.M. 1978. The Archaean Barbacena Greenstone Belt in its typical development and the Minas Itabirite distribution at the Lafaiete district, Minas Gerais, Brazil. An. Acad. Bras. Ci., 50(4):599-600.

PIRES, F.R.M \& PORTO JR.,R., 1986. A mineralização de SnTa-Nb-Li e o granito Santa Rita, São João Del Rei, Minas Gerais. In: CONGR. BRAS. GEOL., 34. Goiânia, 1986. Anais...Goiânia, SBG. v.5, p. 2023-2034.

PIRES, F.R.M.; RIBEIRO, A.; BARBOSA, M.I.M. 1990 Distribuição do "Greenstone Belt" Barbacena na região de São João del Rei, Minas Gerais. In: CONGR. BRAS. GEOL., 36. Natal, 1990. Anais...Natal, SBG. v.6, p. 2941-2951.

PLIMER, I.R. 1980. Exhalative Sn and W deposits associated with mafic volcanism as precursors to $\mathrm{Sn}$ and $\mathrm{W}$ deposits associated with granites. Mineral. Deposita, 15(3):275-289.

QUÉMÉNEUR, J.J.G. 1987. Petrography of the pegmatites from Rio das Mortes Valley, southeast Minas Gerais, Brazil. Rev. Bras. Geoc., 17(4):595-600.

QUÉMÉNEUR, J.J.G. \& VIDAL, P. 1989. Primeiras datações radiométricas dos granitos da região de São João Del Rei (Minas Gerais). In: SIMP. GEOL. MINAS GERAIS, 5. Belo Horizonte, 1989. Anais...Belo Horizonte, SBG. v.1, p. 50-54.

RAO, S.P.K.; SASTRY, R.N.S.; RAJU, S.V. 1989. Scheelite as a prospecting tool for gold in the Ramagiri greenstone belt, Andhra Pradesh, India. Jour. Geoch. Explor., 31:307-317.

ROBERT, F. \& BROWN, A.C. 1986. Archean gold-bearing quartz vein at the Sigma Mine, Abitibi Greenstone belt, Quebec: Part I of II - Geologic relations and formation of the vein system. Econ. Geol., 81(3):578-592.

SÁ, J.H.S. \& KAWASHITA, K. 1976. Idades Rb/Sr de rochas do 
Grupo Macaúbas, MG. In: CONGR. BRAS. GEOL., 29. Ouro Preto, 1976. Bol. Res...Ouro Preto, SBG. v.1, p. 220.

SALDANHA, R. 1946. Estudo da jazida de wolframita de Inhandjara. São Paulo, FFCL/USP. Série Mineralogia, 95 p. (Boletim 8).

SALDANHA, R. \& FRANCO, R.R. 1946. Nota preliminar sobre a ocorrência de volframita e cassiterita em Sorocaba. Min. Met. X(57):107-109.

SANTOS, R.A. \& PEREIRA, R.M. 1983. Nota sobre a ocorrência de scheelita na região de São Tiago, Nazareno e Cassiterita, M.G. Min. Metal., 444:32-33.

SCABORA, J.A. \& PENHA, U.C. 1992. Prospecção geoquímica regional nas folhas Ipanema e Itanhomi/MG. In: CONGR. BRAS. GEOL., 37. São Paulo, 1992. Bol. Res. Exp...SBG. v.2, p.236-237.

SCARPELLI, W. 1991. Aspects of gold mineralization in the Iron Quadrangle, Brazil. In: LADEIRA, E.A. ed. Brazil Gold' 91. The economics, geology, geochemistry and genesis of gold deposits. Balkema, Netherlands. p. 151-157.

SCHORSCHER, H.D., 1978. Komatiitos na estrutura "greenstone belt" - Série Rio das Velhas, Quadrilátero Ferrífero, Minas Gerais, Brasil. In: CONGR. BRASIL. GEOL.,30. Recife, 1978. Bol. Res. Exp....Recife, SBG. v.1, p.292-293.
SILVA, J.M.R.; LIMA, M.I.C.; VERONESE, V.F.; RIBEIRO JUNIOR, R.N. ROCHA, M.L.; SIGA JUNIOR, O. 1987. Projeto RADAMBRASIL. Folha SE-24 Rio Doce. Rio de Janeiro, v.34, p.23-174.

SKAARUP, P. 1974. Strata-bound scheelite mineralisation in skarns and gneisses from the Bindal area, northern Norway. Miner. Deposita, 9(4):299-308.

SMETH, J.B.; SURYA PRAKASH RAO, K.; SCHUILING, R.D. 1985. Gold-scheelite mineralization in the Velegalley schist belt, Andhra Pradesh, India. Econ. Geol. 80:1996-2000.

STEMPROK, M. 1987. Greisenization (a review). Geologische Rundschau, 76(1):169-175.

SUSZCZYNSKI, E.F., 1975. Os recursos minerais reais $e$ potenciais do Brasil e sua metalogenia. 1 ed. Rio de Janeiro, Interciências. 536p.

TEIXEIRA 1992. Contribuição a geologia do "greenstone belt Itumirim-Nazareno (MG). In: CONGR. BRAS. GEOL., 37. São Paulo, 1992. Anais...São Paulo, SBG. v.2, p. 476-477.

VAZ DE MELLO, M.T.; MANDETTA, P.; SABOIA, L.A. 1994. Mapa metalogenético de Minas Gerais. Escala 1:1.000.000 (COMIG).

WERNICK, E. 1981.The Archaean of Brazil. Earth Sci. Reviews, $17(1-2): 31-48$ 